\title{
Ellacuría después de Ellacuría El diálogo filosófico posterior a Ellacuría
}

\section{Introducción}

- Mario Estuardo López Barrientos

- Milton Vladimir Villatoro Díaz

Los distintos estudiosos de Ignacio Ellacuría coinciden en opinar que su asesinato (16 de noviembre de 1989) truncó de manera abrupla un proyecto filosófico, teológico y político de liberación. Once años después de su asesinato nos encontramos en una nueva coyuntura que nos permite rellexionar más detenidamente las posibilidades que nos ofrece su obra. Se han necesilado estos once años para recoger los escritos publicados e inédilos de Ellacuría, sus esquemas de clase y otros apuntes. Ila sido una labor en conjunto, desde la publicación de su obra póstuma Filosofía de la Realidad Histórica (199()), pasando por la edición de toda su obra (Escritos Políticos, 1991; Escritos Filosóficos, 1996 y 1999 "); Escritos Universitarios, 1999; y Escritos Teológicos, 20(1)(1), sumando la realización de por lo menos dieciséis tesis de licenciatura sobre distintos problemas rellexionados por Ellacuría desde la lilosolía, la publicación de un número similar de artículos en la revista Esitudios Centroamericanos, y dos lesis de doctorado, una de ellas aún en preparación. Y esto solamente en nuestra universidad, no digamos aquellos libros que van llegando a nuestra biblioteca tanto sobre su vida como acerca de su obra, la cual abarca una gran diversidad de lemas.

El presente trabajo de investigación pretende ser un pequeño alto en el camino. Desde nuestra condición de estudiantes, el objetivo de este ensayo es el de

* Cuando este número se encontraba en imprenta, UCA Editores publicó el volumen III de los Escritos Filosóficos. (N. del E.)

Ellocurio después de Ellocuría El diálogo filosófico posterior a Ellocurio 
pasar revista y hacer una recensión sobre lo que hay de "Ellacuría después de Ellacuría". Inicialmente, eshozamos un proyecto que abarcaba la recensión de las dieciscéis tesis de licenciatura, la investigación de otros veintidós artículos en la revista Estudios: Centroamericanos, ocho artículos que estaban en la página weh de la UCA — no publicados en la revista ECA - y dos libros sobre Ellacuría, pasando indiscutiblemente por los prólogos a sus distintas obras'. Evidentementc, a medida que la investigación avanzaba, nos vimos obligados a clelimitar bien nuestra área de trabajo y nos enfocamos en los diecisceis arlículos publicados por la revista ECA que tratan a Ellacuría. Después de su recensión. los sistematizamos en tres bloques: Ios que exponen la teoría de Ellacuría; los que utilizan a Ellacuría como referencia para reflexionar una problemática específica; y los que hacen debate frontal a las tesis del mismo Ellacuría. Es correcto señalar aquí que la tesis doctoral del Doctor Samour y su estudio en el salón de clase ha sido imprescindible para poder realizar esta revista con objetividad y comprensión en su carácter de totalidad. En su momento aportamos nuestra valoración a este respecto.

La presentación formal de nuestro trabajo consiste en dos apartados. El primero, meramente descriptivo, consiste en exponer someramente los textos elegidos. Son pequeñas elaborar recensiones sobre lo tralado en ellos, con la idea de dar una noción al lector acerca de lo que se ha escrito desde Ellacuría. El segundo apartado consiste en mostrar los posibles diálogos de debate que han nacido desde las distintas perspectivas de estudio de las tesis ellacurianas. Esta segunda parte es fruto de la primera, y constituye básicamente las conclusiones a las que hemos llegado después de la lectura sobre lo escrito desde Ellacuría. Esperamos haber cometido nuestro propósito y dar al lector pistas para futuras investigaciones, sobre todo teniendo en cuenta que no hace falta inventar el agua, es decir, que las futuras investigaciones no partan de la nada, sino que tomen en cuenta el camino ya recorrido.

\section{Lo que se ha escrito desde Ellacuria}

A conlinuación, presentamos en orden cronológico los distintos artículos que exponen, refieren o confrontan el pensamiento filosófico de Ignacio Ellacuría. La metodología es sencilla: se expone primero la fuente y despućs se hace una breve recensión, intentando dar una idea de la importancia del texto, la situación en que ha sido escrita y el contenido tratado. En ocasiones, se hacen otro tipo de valoraciones críticas.

-Antonio González. Aproximación a la ohra filosófica de Ignacio Ellacuría (ECA 505-506, Noviembre-Diciembre 199(), pp. 979-989).

Un elemento relevante de este artículo consiste en haber sido el primero en publicarse (apenas a un año del asesinato de Ellacuría y compañeros) y ofrecer un panorama completo de la filosofía de Ellacuría. Recordemos que esc año 
Antonio González había estado preparando la edición del libro póstumo de Ellacuría Filosofía de la realidad histórica (UCA editores, 1990).

La tesis principal del artículo sostiene el aporte de Ellacuría a la constitución de una 'filosofía de la liberación' que sea una 'filosofía de la realidad histórica' cuyo punto de partida sería la praxis histórica de liberación. La base de esta filosofía se encontraría en la filosofía de Zubiri. Contiene cinco títulos en los que desarrolla los siguientes temas: Primero, el aporte de Ellacuría de "haber hecho de la filosofía un elemento constitutivo de una existencia dedicada a la liberación"2, es decir, una filosofía como modo de vida cuya función liberadora prima sobre la función académica o sobre la mera transmisión de contenidos filosóficos.

Segundo, su formación filosófica, pasando por el neoescolasticismo, las filosofías de Ortega y Gasset y Bergson, su encuentro en Innsbruck con Heidegger y el existencialismo, hasła que conoce a Zubiri. González establece, además, la relación entre la 'filosofía de la liberación' y Zubiri en dos puntos: (a) el interés de Ellacuría del novedoso tratamiento que hace Zubiri a la historicidad y el posible diálogo que puede hacerse con la filosofía marxista, especialmente con el materialismo histórico; y (b) la idea de esencia como estructura, pero como estructura dinámica.

Tercero, el horizonte de la filosofía de la liberación: la historia. González. señala la inicial comprensión de Ellacuría de la filosofía de Zubiri como un 'realismo materialista abierto', no atado al horizonte griego de la naturaleza, sino en un nuevo horizonte donde "saber y realidad son en su misma raíz. estricta y rigurosamente congéneres"', donde la teoría de la inteligencia es punto radical de partida de la filosofía de Zubiri, pero admitiendo, el prisus de la realidad en la intelección". Después del estudio de Estructura Dincímica de la Realidad, Ellacuría entiende que para Zubiri en la historia se hacen presentes todos los demás dinamismos de la realı lad (la historia como ultimidad) y la historia como "imbricación entre realidad e inteligencia" . De aquí que la filosofía deba ocuparse de lo último de lo real, la realidad histórical.

Cuarto, la revisión de las tesis de Marx, I legel y Zubiri por parte de Ellacuría para proponer que el objeto último de la filosolía sea la realidad histórica. Ahora bien, la realidad histórica presenta un carácler de 'praxis' entendida como "la totalidad del proceso social en cuanto transformador de la realidad lanto natural como histórica”, "donde las relaciones sujeto-objeto no son unidireccionales"”. La filosofía de la liberación quedaría entendida como momento de rellexión de una praxis histórica de liberación, como "aclualización de las máximas posibilidades de lo real" ". Y quinto, la reflexión ellacuriana de la relación teoria-praxis que encuentra respuesta en la historización de la inteligencia. Apoyado en la teoría de la inteligencia sentiente de Zubiri, Ellacuría demuestra: (a) el origen social e histórico de la inteligencia; (b) el destino social e histórico de la inteligencia; y (c) lo histórico como constitutivo de la inteligencia. Por ello, "cual-

\section{9}

Ellacurio después de Ellacuría El diálogo filosófico posterior a Ellacurio 
quier filosofía debe tener conciencia de su propia historicidad, de la praxis social de la que surge, a la que sirve y en la que se mueve"

Por último, Anłonio González concluye especificando que el 'de' de la " $\mathrm{Fi}$ losofía de la praxis histórica" tiene un carácter objetivo, en tanto que señala el objeto, y un carácter subjetivo, en tanto que señala el punto de partida; por ello, la praxis histórica es culminación y principio del filosofar.

-Manuel Domínguez Miranda, Ignacio Ellacuría, filósofo de la realidad latinoamericana, (ECA 529-530, Noviembre-Diciembre 1992, pp. 98.3-998).

A tres años del asesinato de Ellacuría, el autor nos muestra la concepción que Ellacuría tiene del trabajo filosófico desde la situación 'actual' de América Latina, y describe la metafísica de Ellacuría como un realismo materialista abierto, desde la nueva concepción de inteligencia y de realidad de Zubiri.

A nuestro criterio, el principal mérito de este artículo consiste en la descripción de la idea de filosofía que Ellacuría liene para América Latina. A partir de los textos "El objeto de la filosofia" y "Función liberadora de la filosofía", Domínguez esboza la naturaleza, objeto, función y posibilidad de la filosofía latinoamericana en Ellacuría y concluye que "por esto no se identifica el pensamiento de Ellacuría con la búsqueda de características peculiares o exclusivas a una 'filosofía latinoamericana'.

Para él, cualquier filosofía no podía ser otra cosa que la actualización, en una determinada época y situación cultural, de los objetivos, funciones y características que son esenciales a toda filosofía"', de tal manera que Ellacuría se refería siempre a una filosofía a secas y pocas veces a una filosofía latinoamericana. La tarea de la filosofía tendría las siguientes características: (a) la realidad histórica como objeto de la filosofía; (b) la realidad histórica no excluye necesariamente la realidad transhistórica: Dios; y (c) la filosofía es iluminación teórica de los procesos sociales ya que encarnan la realidad histórica. De esta forma, se concibe la filosofía como un momento de la praxis, pero con una tarea eminentemente ética: "no se puede estar del lado de la opresión y de la injusticia, pues éstas reprimen la verdad y retrasan, o impiden totalmente, las dinámicas históricas hacia la perfección de la humanidad"'", que necesita el reconocimiento de sus exigencias específicas, a saber: el rigor lécnico-metodológico y la adecuada ubicación del filósofo frente a la realidad, de lo contrario esperaría una labor estéril y contraproducente.

La función liberadora de la filosolía, en su doble capacidad (crílica y creadora), va orientada principalmente a la ideología dominante, o mejor dicho contra la ideologización (ocultamiento y distorsión de la realidad), para des-ocular y construir un nuevo lenguaje o ideología". Resalta la idea que la vehiculación de las ideas de liberación está en manos de las debidas fuerzas sociales, donde al filósofo no le corresponde la realización de la política, sino la reflexión desde el 
verdadero sujeto de liberación: "las fuerzas sociales que, conscientes de la inhumanidad que encierra la opresión, reaccionan contra ella"'2 . Concluye el autor que para Ellacuría, cualquier intento de filosofía latinoamericana de inspiración cristiana tiene que ser 'filosofía de la liberación', a manera de no caer en defender un status quo e ideologizar una situación de opresión.

El otro tema que Domínguez trata es acerca de la metafísica de Ellacuría. En este punto aclara la relación Ellacuría-Zubiri. Ellacuría fue discípulo, colahorador y amigo íntimo de Zubiri, pero no fue simplemente un repetidor más de Zubiri: "no repetición exacta, sino reelaboración en orden a resolver problemas que se presentan en la realidad latinoamericana"1.?. Dicho esto, describe las características de su metafísica en tres puntos: hacia un nuevo realismo, inteligencia sentiente, y dinamicidad y poder de lo real. Si bien vio en Zubiri un realismo materialista abierto, la preocupación de Ellacuría fue la reflexión del carácter histórico de la realidad, de tal manera que fuera una (unidad física de todo Io real), dinámica (dialéctica en algunos procesos sociales), estructural (compuesto de notas en respectividad) e histórica.

- Rafacl Díaz-Salazar, La crítica cristiana a la civilización del capital, Aportación de la Doctrina Social de la Iglesia a la construcción de un nuevo socialismo. (ECA 541-542, Noviembre-Diciembre 1992, pp. (9)9-1(14).

Hemos incluido este artículo por la utilización consciente del autor del término ellacuriano "civilización del capital" en contraposición a "civilización de la pobreza"14. Sin embargo, el autor prescinde totalmente del pensamiento de Ellacuría y utiliza las tesis de la Doctrina Social de la Iglesia para pensar la construcción de un nuevo socialismo sobre la base de la democracia económica. Por esto, este artículo carece de importancia según nuestros intereses.

- Carlos Acevedo, El legado filosófico-politico de Ignacio Ellacuria. (IECA 541-.542, Noviembre-Diciembre 1993. pp. 1(189-11(17).

Artículo extenso en el que el autor trata los siguientes cuatro puntos: (a) señalar la influencia de la metafísica de Xavier Zubiri sobre el pensamiento maduro de Ignacio Ellacuría, así como su talante socrático de quehacer filosófico; (b) exponer el método fundamental con que Ellacuría procedió a lo largo de su reflexión filosófica; (c) la propucsta de realidad histórica como objeto de la filosofía; y (d) los rasgos fundamentales de que para Ellacuría sería una filosofía de la liberación.

En este artículo, Acevedo reloma algunas aseveraciones de Domínguez Miranda y de Antonio González. Del primero, la idea que Ellacuría no repite a Zubiri nada más, sino que se permite una creativa reclaboración de su filosofía de cara enfrentar los problemas radicales de América Lalina"s. Además. señala que "cierlamente, Ellacuría no produjo una filosofía original en el sentido de un organon conceptual propio o de un sistema filosífico estrictamente lal. Su órga-

Ellocurio después de Ellocuría El diólogo filosófico posterior a Ellocurio 
no conceptual es, en lo fundamental, el de Zubiri"'s. De Antonio González, retoma la idea de que el legado de Ellacuría no consiste tanto en una filosofía concrela, sino en su modo de hacer filosofía, y lo cita: "no cedió a la moda jamás, no habló nî escribió en busca de popularidad o de recompensa material alguna, no buscó halagar a nadie y menos a sí mismo, huscó con todas sus fuerzas no auto-engañarse"1?. Desarrolla así cl valor tcorético y el valor ético del filosofar, señalando en su debido momento los matices de la politicidad de la filosofía. Aquí también reconoce que Zubiri rcalizó un pathos más esclarecedor que transformador't.

Por otro lado, sobre la posibilidad de una filosofía cristiana en Ellacuría, Acevedo retoma el señalamiento de Rodolfo Cardenal de que Ellacuría fue más teólogo que filósofo, y esto por la simple razón que "para América Latina era más urgente la teología para una praxis más eficaz de liberación" ". Sin embargo, aunque en un nivel práxico-existencial fuera más necesaria la leología, era formalmente filosófico, sobre todo en virtud de su apertura metafísica intramundana a la realidad transmundana (Dios). Sobre este punto concluye: "sin embargo no hubo nunca en esic planteamiento un ápice del esquema escolástico de la filosolía como ancillac theologia" "20, sosteniendo la filosofía como saber autónomo.

Otro aporte de Acevedo que da luces para conocer bien a Ellacuría, es su tratamiento acerca del método filosílico de Ellacuría. Para éste había que atenerse a los hechos reales ${ }^{21}$ y renunciar a la inteligencia era un suicidio intelectual. La pregunta metodológica fundamental consistía en cómo aclualizar la realidad en la inteligencia, donde claramente señalaba una doble vía melodológica: la vía de realidad y la vía de verdad. Acevedo prolonga este análisis señalando la prioridad epistemológica de la realidad y el método de la lilosofía de partir de Ios dalos de las demás ciencias y saberes.

Los otros clos puntos (el objeto de la filosofía y la función liberaclora de la filosofía) los expone un tanto más tradicionalmente. Sin embargo, innova al incorporar el constitutivo carácter biológico-sentiente de la realidad (la base biológica de la realidad humana) y la inteligencia como un summum de realidad, retomando otros textos de Ellacuría, sobre todo en su acompañamiento a la antropología de Zubiri². En su trato de la Función Liberadora de la Filosofía. Acevedo recuerda que Ellacuría, en contraposición a Heidegger señala "i.por qué existe nada en vez. de ente?"’3. Su última novedad es el señalamiento de que Ellacuría entendía las 'mayorías populares', entre otras cosas, como principio de corrección epistemológica y ética de la praxis liberadora; sobre todo resaltando la diferencia entre liberalización (vía de los pocos fuertes) y liberación (camino de las mayorías)".

-lléctor Samour, Itistoria, praxis y' liberación én el pensamiento de Ignacio Ellacuria, (ECA 541-542, Noviembre-Diciembre 1993, pp. 11(19-1127).

Este arlículo aparecerá casi en su tolalidad en una recopilación de textos sobre Ellacuría ${ }^{25}$, sólo que de manera actualizada. Pretende ser un resumen del 
pensamiento filosófico de Ellacuría y esclarecer su proyecto de claborar una filosofía de la liberación como momento teórico especílico de una praxis de liberación ${ }^{2 h}$. Recorre distintas temáticas: Primero, la relación Zubiri-Cillacuría, resaltando el esfuerzo intelectual de Ellacuría de "continuar, aplicar o historizar el pensamiento zubiriano en el contexto latinoamericano"'-?. Ello le lleva al autor a sumarse a las apreciaciones de Domínguez Miranda de que Ellacuría no husca una 'filosofía latinoamericana' de características peculiares, sino de ser filosofía nomás, pero a la altura de los tiempos, reconociendo que la lilosofía pura de Zubiri era apta para pensar filosóficamente la liberación.

Segundo, la afirmación de Ellacuría de tener la realidad histórica como ohjeto y horizonte de la filosofía. En este punto, el autor insiste en depurar la tergiversación del pensamiento ellacuriano de ser un realismo naturalista al estilo griego y discute la fundamentación del carácter de la historia como summum de realidad, como "unidad más englobante y manifestativa de la realidad"-2x. Tercero, analiza el concepto 'historia' como carácter de la praxis. Por praxis entiende "la totalidad del proceso social en cuanto transformador tanto de la realidad natural como histórica"29. Señala el carácter metafísico de la praxis histórica como praxis de liberación. Al mismo tiempo, confronta esta concepción de realidad histórica ante la concepción moderna y postmoderna de historia, sobre todo frente a la afirmación de Fukuyama del 'fin de la historia'. Dirá que para Ellacuría el final de la historia se puede pensar desde tres perspectivas: (a) físicamente, como cambio de las condiciones cósmicas, que no le compele a la realidad histórica y que no está en manos de la humanidad hacerle frente; (b) desde la posibilidad de la humanidad de autodestruirse, lo que sugiere una responsabilidad ética; y (c) desde la perspectiva 'maltusiana', en tanto que los consumidores de recursos aumentan en proporción mayor que la renovación de esos recursos, debilitando las posibilidades históricas de hacerse cargo de la misma historia ${ }^{311}$. Aquí entran también las apreciaciones que Ellacuría hace a la "civilización del capital' en sus componentes materiales, económicos y socioculturales de alienación. En contrate, la 'civilización de la pobreza' que promucve la humanización de la realidad histórica (material, económica y socio-cultural).

Cuarto, la definición del concepto de 'libertad' para Ellacuría y su relación con la naturaleza: la libertad como libertad 'de', 'en' y 'desde' la naluraleza". La liberación sería, entonces: (a) un proceso de posibilitización para que los hombres sean actores y autores de su propia realidad histórica; (b) que en lo personal se manifiesta como un proceso de 'conversión', y en lo social como un proceso de 'transformación' o 'revolución’; y (c) no sólo proceso, sino proceso colectivo, a diferencia de la 'liberalización individualista' que escinde la tolalidad de la realidad en favor de unos cuantos"'. Y quinto, el autor concluye señalando trece elementos de la dimensión ética de la filosofía en América Latina. 
-Rolando Alvarado, Ignacio Ellacuria: de la liberacion de la filosofia a la filosofía de la liberación, (EC:A $541-542$, Noviembre-Diciembre 1993, pp. 1129. 1142).

El autor ofrece una clave de lectura "que respete ese doble carácter de la producción filosófica ellacuriana" " a saber: la inspiración zubiriana en el pensamiento filosófico de Ellacuría y su la originalidad de Ellacuría. Hablamos pues de dos niveles:

Primero, sobre la inspiración zubiriana en Ellacuría se reliere especílicamente a su arlículo La superacion del reduccionismo idealista ('n Zuhiri". Este reduccionismo consiste en lo que Zubiri llama la entificación de la realidad y la logificación de la inteligencia, como modos idealistas en los que ha incurrido la historia de la filosofía desde Parménides. Ante esto, Cillacuría propones las cinco grandes líneas en que Zubiri supera tal 'idealismo`: la reificación del ente; la inteligización del logos; la reintegración e historización del hombre; la desnaturalización de la historia; y la des-objetivación de Dios en la fundamentación de la praxis humana ${ }^{35}$.

Segundo, la originalidad de Ellacuría consiste en reelaborar la filosofía de Zubiri para enfrentar los problemas de América Latina. Destaca aquí, su visión de la politicidad de la filosofía. "h . La politicidad de la filosofía queda fundamentada desde los tres modos en que la lilosofía se entiende a sí misma, siguiendo a Zubiri: como saber acerca de las cosas; como dirección para el mundo y para la vida; y como forma de vida que, por tanto, acontece ${ }^{37}$. Para Ellacuría en cada uno de estos modos está intrínsecamente una referencia a lo político. Ellacuría distingue entre filosofía de la política. que estudia lo político, y filosofía política, que consiste en reconocer la dimensión política de toda filosofía. La falsa politicidad de la filosofía puede presentarse cuando: subordina la filosofía a intereses que no le competen, como obtener el poder; se hace una superficialización inmediatista de los temas; se utiliza el filosofar según su efectividad inmediata y directa; es acrílica frente al acontecer político; y cuando considera el filosofar formalmente autónomo a lo político. El autor nos recuerda que si Ellacuría fue lo bastante detallado y concreto para señalar lo que no debería ser la politicidad de la filosofía, fue lo bastante amplio y general para caracierizar lo que sí debería ser su verdadera politicidad ${ }^{2 k}$, a saber, segín su efectividad. Politicidad equivale entonces a efectividad, en cuanto pide que "sea un pensar que surja desde una situación concreta y que esté anclado en la totalidad de lo real". Es una efectividad de carácter social, en tanto que nosotros como la filosofía estamos vertidos hacia los demás. El objeto y punto de partida del filosofar sería, por lanto, la praxis histórica.

La dimensión politica de la filosofía respondería a tres momentos: el teorético, el práxico y el histórico; en otras palabras, la inteligencia teorética, la inteligencia práctica y la inteligencia histórica ". Por esta dimensión política intrínse- 
ca, el filósofo debe estar consciente del 'desde dónde' hace filosolía. Ellacuría se situó “desde' la praxis histórica de liberación "t". Por último, el autor enumera las implicaciones de la dimensión política de la lilosolía: reconocer la dimensión política intrínseca de todo filosofar; desear que la lïlosolía realice esta dimensión eficazmente; estar consciente de que la dimensión política del filosolar se puede actualizar como de modo opresor o de modo liberador, emancipador; y la alectación de la dimensión política en el filósolo debe actualizarse como siendo un "intelectual inserto", cumpliendo el "hacerse cargo de la realidad, cargar con la realidad y encargarse de la realidad", como afirmaba Ellacuría".

-Antonio González., Orden mundial y liberación, (ECA .54\%, Julio 1994, pp. $629-(.52)$

Este arlículo intenta fundamentar la posibilidad de un vínculo social que permila pensar la sociedad mundial. En él, la filosolía de Ellacuría ha sido tomada como referencia explícila en tres ocasiones: las notas de pie de página 2. 19 y $20^{42}$. La primera utiliza la lilosolia de la realidad histórica de Ellacuría para desmitilicar las tesis del lin de la historia. Señala: "Ia historia, como dinamismo de apropiación de posibilidades, solamente se terminará con el fin de la especie humana"t?. La segunda y la tereera referencia a Ellacuría es para hacer una valoración ética de la conliguración mundial actual: el capilalismo. Desde el arlículo Utopia y Proferismo desde América Latinat, Antonio subraya la crítica de Ellacuría a la "civilización del capilal": "ello lleva naturalmente a pensar que los niveles de desarrollo y consumo de los pucblos más ricos solamente son posibles si se mantiene esta desigualdad radical en el seno de la humanidad, pues los recursos del planeta no son de hecho sulicientes para que esos niveles sean universalizados".15.

- Héctor Samour, Marco térico-practico para la construcción de un orden democrático en El Salvallor (ECA .54.3-544, Enero-Febrero 1994, pp. 3.3-5.5).

Este arlículo lambién cila a Ellacuria como referencia en dos ocasiones explícilamente: en su diagnóstico de la 'democracia' en El Salvador y en su diagnóstico de las 'masas' populares. La primera hace referencia al arlículo de Ellacuría "La fachada democrálica" "t". Dice: "en El Salvador la democracia nunca logró realizarse incluso en el período de la guerra donde la "lachada democrátical era un componente de la estrategia de contrainsurgencia”. I a segunda referencia hace alusión al artículo "I a cuestión de las masas" "w. Reconoce la debilidad y atomización de la sociedad civil "cuyas causas hay que buscarlas en la guerra, en los programas de ajuste estructural de corte neoliberal, y en los errores cometidos por las organizaciones político-militares del FMLN”. La crítica de Ellacuría al FMLN consiste en que irrespelaron "la identidad cultural, de raíz profundamente cristiana. lorzándoles a entrar en un proceso de mililancia polílica que no estaban preparados. Se les trató de imponer el marxismo-leninismo, como interpretación cientílica e indiscutible de la realidad social, de lal

Ellocurio después de Ellocurio El diálogo filosófico posterior a Ellocurio 
manera que a 1981 ya no exislían organizaciones populares ni ningún otro movimiento social. Creció la milicia del FMLN, pero quedó abandonada la población", la cual terminó por reunirse en seclas, en el ámbito religioso; en sindicatos y cooperativaš en una reforma agraria contrainsurgente, en el ámbito social: y en acciones de partidos políticos de derecha. Con esto concluye que no hay que seguir recetas de arriba o de afuera, sino partir de la misma autonomía de los movimientos sociales.

-Héctor Samour, Crítica radical al neoliberalismo (ECA 552, ()ctubre 1994, pp. 1069-1101).

Este artículo también toma de referencia a Ellacuría en tres ocasiones: las dos primeras para crilicar el concepto liheral de libertad, y el tercero para valorar éticamente el actual capitalismo como no universalizable. En la crílica al concepto liberal, el autor cita dos fuentes de Ellacuría: "En torno al concepto y a la idea de liberación" y "Filosofía de la realidad histórica"th. Desde ellos resalta la crítica de Ellacuría del conceplo liberal de libertad como unilateral, fundado en la propiedad privada y la riqueza, y su propuesta de, en cambio, un "concepto integral de libertad referido a los pobres y a la pobreza y que se concrele históricamente como proceso de liberación". La tercera fuente que utiliza de Ellacuría es su artículo Utopía y profetismo desde América Latina" para poner en evidencia la "malicia intrínseca del capitalismo" y su carácler no universalizable. Además, el señalamiento que América Latina es el "lugar privilegiado para la universalización de un futuro utópico".

-Omar Serrano, El método de historización de los conceptos de Ignacio Ellacuria, (ECA 553-554, Noviembre-Diciembre 1994, pp. 1245-1249).

Debido a su extensión, este no es propiamente un arlículo sino un comentario. El autor sostiene que el método de historización "es una manera de combatir los presupuestos filosóficos de la historia, que en sus consecuencias reales, siempre condenan a las grandes mayorías empobrecidas" "s". Sobre la base de tres escrilos de Ellacurías1, el autor reloma los términos ellacurianos: 'concepto histórico', como concepto operativo a diferencia del concepto abstracto, universal, de las ideologías dominantes; 'historización' como principio de des-ideologización y principio de verificación en el liempo. Con ello, el método de hisiorización de los conceptos tiene las siguientes funciones: (a) verificar si un conceplo da de sí en la realidad; (b) descubrir si ese concepto está al servicio de los grupos privilegiados que reivindican ese concepto; (c) identificar los condicionamientos que impida la realización del concepto y cuales los que lo ponen en marcha; y (d) cuantificar el tiempo prudencial para constatar un grado aceptable de cumplimiento (deber ser) ${ }^{52}$. Por último, el aulor se pregunta por los fundamentos que utiliza Ellacuría para sostener la tesis de que esta tarea de historización de conceplos deba hacerse 'desde' las mayorías populares: Primero, porque en lodo pensamiento de tipo estruclural (Aristóleles, Santo Tomás, Hegel, Marx, Zubiri), 
la unidad es anterior a las partes y cita a Zubiri: "la unidad domina, es un prius respecto de la posición de cada nota aisladamente considerada" "; en cambio, en el capitalismo está claro el predominio de la parte sobre el lodo, de la menor (disgregadora) sobre la mayor. Y segundo, en el ámbito episiemoligico, porque nos vemos obligados a optar "por el que creemos es el mejor lugar para conocer"s. Dice: "está más cerca de la verdad quien se silúa desde las mayorías populares, y no desde la clase dominante que ideologiza los conceptos de acuerdo a sus lines".

-Roberto Valdés, La evolución del pensamiento filosófico de Ignacio lillacuria, ([C.A 577-578, Noviembre-Diciembre 1996, pp. 1(129-1047) ${ }^{55}$.

Este artículo adquicre relevancia por ser el primero en eshozar posibles líneas para hablar de una evolución desde el joven Ellacuría hasta el Ellacuría más maduro. Los artículos precedentes han sido resúmenes del pensamiento filosólico de Ellacuria desde su encuentro con Zubiri. Éste, en cambio, se atreve a tratar de encontrar los intereses del joven Eilacuría. Nuestra apreciación al respecto, desde la lectura de la tesis doctoral del Dr. Samour, es que si bien el autor ha of recido textos y pistas de los posibles intereses juveniles de Ellacuría, no ha logrado 'acertar' en sus conclusiones, es decir, las citas están bien pero no las conclusiones a las que llega a partir de lales citas. Sin embargo, presentamos aquí el resumen de sus tesis.

El autor aclara que no tiene por objelivo presentar la evolución completa del pensamiento de Ellacuría, sino en resaltar que Ellacuría tuvo un proyecto filosófico inicial que luego abandonó en pos de una teología de la revolución y una filosofía politica. Para Valdés, Ellacuría desde sus 25 años luvo un proyecto filosófico 'bien determinado' que consistía en sentar las hases para una nueva filosofía cristiana ${ }^{\text {sh }}$. Esto es pensable en tanto que para Eallacur ía, "el cristiano no tenía suficiente con su cristianismo como respuesta intelectual y como actividad vital" "47. En esta búsqueda de Ellacuría, Valdés distingue dos períodos: de 1955 a 1963 y de 1963 a 1967. El primero de ellos es la inserción de tillacuría en el neotomismo. Como neoescolástico, Ellacuría se perfiló en la línea de avanzada en la Iglesia Católica de ese entonees. Sin embargo, resalta el interés de Eallacuría de hacer una síntesis entre la filosofia tomista y las filosolias contemporíneas, sobre todo la de Ortega y Gasset. La conciliación que proponía era establecer una complementación jerárquica. Ellacuría admiraba en (Ortega "su vitalismo y su visión dinámica de la realidad y en particular de la historia que tanto contraslaban con el esencialismo y el inmovilismo aristotélico-tomista" ". Clogia el autor la audacia de Ellacuría de valorar positivamente a Ortega cuando éste era públicamente temido por la Iglesia española y por proponerse hacer su propia síntesis de filosofía cristiana. En el segundo período Ellacuría ya conoce la filosofía de Zubiri y ve en él, según Valdés, "la posibilidad de una filosofía cristiana trans-escolástica y trans-existencialista" "s. Debido a su contacto con Zubiri, Ellacuría ya no tenía por qué "recurrir ni a la filosofía lomista ni a la

Ellocurío después de Ellocurio El diálogo filosófico posterior a Ellocurio 
filosofía existencialista”. Más adelante, sostiene Valdés que la problemática de la filosofía cristiana vuelve a aparecer en Ellacuría cuando un curso de introducción a la filosofía a los futuros sacerdotes de Bilbao.

Valdés prosigue señalando la evolución siguiente del pensamiento de Ellacuría hasta 1972. Para ello dice que Ellacuría, siempre con el fin de servir intelectualmente a la Iglesia, deja el proyecto de filosofía cristiana por dos razones: primero,

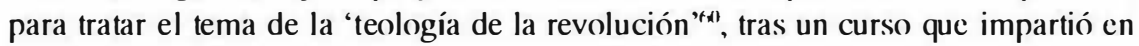
1968 en Medellín; y, segundo, porque se dedicó a trabajar más de cerca con y sobre Zubiri, muestra de ello es la publicación de siete artículos sobre Zubiri en ese período". Hacia 1971, tras una charla sobre "filosofía y política" Ellacuría vuelve a la filosofía con nuevos intereses, en la apreciación de Valdés.

Como expresamos al inicio, las tesis de Valdés no se sustentan a partir de las citas que retoma, deja de fuera dónde entra su "Filosofia de la realidad histórica", que si bien es publicada póstumamente por Antonio González hasta 199(), fue redactada en 1976. Por su parte, el doctor Samour critica que no está claro la búsqueda expresa de Ellacuría de una 'nueva filosofía cristiana' ni antes ni después de conocer a Zubirif ${ }^{\text {}}$, además que tampoco es adecuado mezclar los saberes e intereses filosóficos con los teológicos para determinar la evolución 'intelectual' de un hombre polifacético.

- Ricardo Roque Baldovinos, Los escrios estéricos de Ignacio Ellacuria, (ECA 577-578, Noviembre-Diciembre 1996, pp. 1(052-10.5.5).

Es un comentario donde el autor hace referencia a los sicte artículos de reflexión estética escritos por Ellacuría entre 195.5 y 196.3 , y publicados en Escritos Filosóficos I (UCA editores, 1996). Reconoce la influencia de Ángel Martínez en Ellacuría y señala la preocupación del mismo de reunir los temas poesía, filosofía y religión. Ellacuría está especialmente preocupado por la representación artística de la dimensión religiosa.

Tal vez un aporte importante de este comentario es la referencia al prólogo que Ellacuría escribió y que "por razones de orden editorial" no apareció en los Escritos Filosóficos $I^{\text {h? }}$. En ćl, Ellacuría dice: "pocas cosas tan necesarias en El Salvador como la poesía. Estamos tan atrapados por la materialidad de la existencia cotidiana y por la unidimensionalidad de la dimensión política-militar, por la urgencia de la acción efectiva, que se va reduciendo nuestro ser y se va deshumanizando la condición nacional como forma particularizada de la condición humana". Además, su visión de la 'razón poética' que nos ayuda "a comprender lo que en realidad de verdad está pasando en el país".

-Antonio González, Fundamentos filosíficos de la civilización de la pohreza, (ECA 583, mayo de 1997, pp. 417-426).

En este artículo el autor reflexiona los fundamentos de lo que Ellacuría llamó 'civilización de la pobreza' como modelo alternativo de la 'civilización del

\section{8}

Realidad 83, 2001 
capital', de carácter universalmente inviable e intrínsecamente excluyente. Ubica su reflexión desde el debate contemporáneo entre las éticas del discurso de Apel y Habermas y las éticas de la liberación de Dussel y Ellacuría. Al contraponer a Apel con Ellacuría, dice: "Ambos pensadores constatan que la forma occidental de vida no es universalizable. Aunque Ellacuría, a diferencia de Apel, no proviene de una tradición kantiana de la universalización como criterio moral, citando explícitamente a Kant. Para ambos filósofos, la universalización de la forma de vida occidental causaría una crisis ecológica tan profunda que haría prácticamente imposible la sobrevivencia de la humanidad sobre la tierra" Ambos autores extraerían conclusiones diferentes. Baste reconocer que "mientras la ética de la liberación parte de los pobres, la ética del discurso parte de las comunidades de comunicación realmente existentes”.

Después de definir la necesidad de una 'civilización de la pobreza', donde haya posibilidades de supervivencia para todos, retomando el planteamiento de Ellacuría $^{\text {ht }}$, Antonio González. se dedica fundamentar filosóficamente una alternativa de sociedad. Dice: "Desde la perspectiva de la "civilización de la pobreza' es posible, en cambio, la pregunta sobre si todos los presupuestos del diálogo son aceptables" de la praxis", una prolongación del pensamiento de Zubiri, desde una alteridad radical en los actos donde la realidad se actualiza en la inteligencia como 'de suyo": "la alteridad, en este sentido, no es una experiencia contingente, sino un carácter ineludible de todo acto humano. Por eso, la alteridad puede ser considerada como un momento trascendental de nuestros actos" ${ }^{\text {"' }}$. Y prosigue definiendo el lugar de la razón en las estructuras de la praxis, o mejor dicho, del uso práxico de la razón: "Esta elección no es arbitraria, sino que pende de lo que pensemos que son las cosas con independencia de nuestra experiencia" "(1"; y más adelante: "La razón no es un momento extrínseco a nuestra praxis, sino una dimensión constitutiva de ella, pues cualquier opción entre diversas posibilidades exige un uso práctico de la razón"’”".

Entonces se pregunta por el principio de universalización, dice: "El 'principio de universalización', considerado desde esta perspectiva, no es un intento etnocéntrico de imponer mis propias categorías a los demás. Es más bien el resultado de un dinamismo racional que tiende a poner a mi persona, mis intereses y mis categorías en el mismo plano que las personas, los intereses y las categorías de los demás"7l. Ante la pregunta de qué diferenciaría este planteamiento del de Kant, responde: "Es interesante recordar que Kant había hablado de un 'hecho de la razón'. También aquí hemos procedido a analizar la razón práctica como un hecho. Sin embargo, en la filosolía de Kant, el hecho de la razón aparece como una simple conciencia inmediata del deber. En cambio, nuestro análisis de la razón como hecho nos ha mostrado algo muy distinto. El hecho de la razón no es una conciencia inmediata del deber, sino un dinamismo que surge a partir de aquella alteridad que encontramos en todos nuestros ac- 
tos"72. En otras palabras, mientras para Kant la razón es un a priori, para Zubiri es un a posteriori, una marcha desde la alteridad radical en la aprehensión. Entonces, la étiça queda fundamentada: "el dinamismo de la razón práclica representa ya una obligación primordial: la de situar a las demás personas en el mismo plano que la propia persona"’’, además, que "la razón práctica es indefectiblemente una razón históricamente siluada"74.

El autor concluye: "Aquí no hemos abandonado la praxis, ni siquiera en nombre de una metafísica de la vida. Hemos permanecido en el análisis de la praxis, y hemos encontrado en la razón práctica un hecho ćtico. Y esta razón no fue considerada como una facultad, sino simplemente como un acto director de nuestra opción de posibilidades. En la praxis misma encontramos estructuras éticas que la puedan guiar. (...) Desde la perspectiva de una ética praxcológica es posible cuestionar la forma de vida occidental, en la medida en que no es universalizable. (...) En cambio, una ética praxeológica tiene que esbozar la utopía de una civilización de la pobreza. Esta utopía no es una simple visión ideal, sino el intento real para hacer compatibles las formas de vida de todos los seres humanos en un planeta más justo"7s.

-Sajid Herrera, El aporte de la filosofia latinoamericana a los dercichos humanos, (ECA 589-590, Noviembre-Diciembre 1997, pp. 1157-1168).

El autor pasa revista de algunos pensadores latinoamericanos como Zca, Miró Quesada, Serrano Caldera, Boff, Rojas, Ellacuría y Dussel para visualizar "cl aporte que la filosofía gestada en Latinoamérica ha ofrecido a las teorizaciones de los derechos humanos en los últimos años"7n, especialmente en las últimas tres décadas. Sus reflexiones abarcan desde la pregunta por la posibilidad de una filosofía latinoamericana, caracterizada principalmente por dar respuesta y buscar fundamentos a una situación "cargada de procesos de dependencia y procesos de liberación" "77; el abordaje del problema de los derechos humanos como un problema más radical entre teoría y praxis; la situación de los derechos humanos en Latinoamérica y el aporte de fundamentación filosófica: Lo humano y lo colectivo como punto de partida, el paso de la concreción a la universalización. y su actualización en un horizonte postmoderno.

En concreto, el aporte de Ellacuría a la teorización de los derechos humanos, reconocido por el autor, consiste en su método de 'historización de los conceptos'. La propuesta melódical de historización de los conceptos consiste en "verificar, constatar y examinar las condiciones reales de los derechos humanos que han sido proclamados para desmentir su falsedad o reafirmar su realización" Tienc dos potentes características: la relación teoría-praxis y la relación denuncia-utopía. La primera, en lanto que permite constalar la verdadera efectividad práctica de un derecho y señalar qué tipo de acción deberá emprenderse para su cumplimiento mínimamente aceptable". La segunda, porque "la denuncia del incumplimiento de los derechos humanos tendrá que acompañarse de ideales 
utópicos que son exigibles y que permitirán la toma de conciencia de un problema que puede ser superado" ${ }^{\text {(H). }}$.

-Jordi Corominas, Materia y Praxis, (ECA 613-614, Noviembre-Diciembre 1999, pp. 1009-1032).

A nuestro modo de ver es el artículo más interesante y que abre mayor debate no sólo en la interpretación de Ellacuría sino en la radicalidad misma del filosofar. La tesis de fondo consiste en demostrar que antes de toda metafísica, de toda teoría de la realidad como realidad 'allende', está el análisis de los actos. Es la teoría de Antonio González y su praxeología, que enfrenta radicalmente no sólo a Ellacuría y su 'filosofía de la realidad histórica', sino también a Zubiri y su 'realismo trascendental'.

El mérito de Ellacuría consiste en hacer una metafísica de la realidad histórica, a partir de su lectura de "Sobre la esencia" y de "Estructura dinámica de la realidad". Este realismo metafísico que Ellacuría elabora desde el pensamiento de Zubiri, es en un materialismo abicrto que supera, por un lado, el idealismo de la filosofía moderna cuyo pecado es haberse fosilizado en logificaciones intelectivas $y$, por otro, el materialismo dialéctico entendido como teoría cosmológica que ha acompañado al materialismo histórico ${ }^{\mathrm{kl}}$. Para Corominas, las últimas reflexiones de Ellacuría sobre la realidad histórica lo acercan a los planteamientos de la filosofía de la praxis ${ }^{k 2}$.

Cierlamente, Ellacuría inserta la filosofía de la liberación en una praxis liberadora. Los requisitos de esta filosofía son tres: primero, la loma de consciencia de la humilde larea de la filosofía, en cuanto que las ideas solas no cambian las cosas sino que necesilan de fuerzas sociales que las realicen; segundo, el mantenimiento de la autonomía y del modo técnico y específico del filosofar; y tercero, acompañar la praxis liberadora con un bagaje térico sobre puntos esenciales (teoría de la inteligencia, de la realidad, del hombre, de la sociedad y la historia, la ética y la filosofía de la religión) de acuerdo a las necesidades de América Latina ${ }^{\mathrm{x}}$. Siguiendo el afán de radicalidad del mismo Ellacuría, Corominas cuestiona las consecuencias de este acompañamiento teórico a la praxis liberadora, por varias razones: Primero, no es posible asumir dogmáticamente que la praxis liberadora sea "aquella que realizan los oprimidos, explotados y excluidos del sistema en vistas a transformarlo", en tanto que hay prácticas delictivas que efectivamente transforman el sistema, pero no en su humanización y liberación. Segundo, porque muchas veces "acciones y fuerzas, otrora ejemplares y pretendidamente liberadoras, apenas pueden esconder hoy, bajo su lenguaje revolucionario, la corrupción y la manipulación de los pobres" Es el ejemplo del actual sandinismo en Nicaragua, para no ir tan lejos. Tercero, porque no está nada claro qué praxis sean liberadoras y cuales opresoras, es decir que el componente ético de la filosofía pende del compromiso del filósofo con las 'víctimas de lodo poder' donde nadic se escapa de ser algunas

Ellocurio después de Ellocurio El diálogo filosófico posterior a Ellacurio 
veces víctima y otras victimario ${ }^{\mathrm{ks}}$. Cuarto, porque se privilegia la praxis social en detrimento de la paciente labor aislada del filósolo, pero lambién del pocta, del científico, etc. Dice: "en cierto modo, la disciplina que cruza ortogonalmente todos los saberes y todas las acciones humanas es la ética" "’h y ésta sugiere que las ciencias de alguna manera lienen la necesidad imperativa de melerse a fondo en su propia disciplina de tal modo que de nada sirve, por ejemplo, "una teoría social crítica que además de momento crítico no desarrolle una leoría social potente" ${ }^{\mathrm{N}}$. Con todo, Corominas reconoce la invilación aulénlica de Eallacuría a un equilibrio entre, por un lado, una existencia socrálica proclive a la "soledad" para conservar su mordiente crítico y, por otro, el compromiso proclive a la politización de la filosofía y el filósofo en su solidaridad con las víclimas de todo poder"

Corominas entonces pasa a reflexionar sobre el problema del 'malcrialismo' en la historia de la filosofía. El materialismo como tesis metafísica postula que "todo lo real es material" " ${ }^{\prime}$ ' pasa revista a los distintos materialismos: el de los atomistas y sofistas griegos, el de los mecanicistas ilustrados del siglo XVII y $X V I I I$, el del siglo XIX, el dialéctico y el emergentista del siglo XX. Concluye que una filosofía liberadora no necesita de un materialismo metafísico. Entonces revisa el materialismo histórico. Este se diferencia en que no es una tesis metafísica sobre la realidad, sino una teoría social que no implica $x$ o y metafísica materialista ${ }^{410}$. De hecho, hacia se encaminaba el mismo Gramsci, el punto intermedio entre la hipostatización del espíritu como de la materia, en la praxis humana. Esto lo lleva a término, según Corominas, más que Zubiri, Antonio González" ${ }^{41}$. Presenta entonces los lineamientos esenciales de la praxeología como filosofía primera. La praxeología supera, a criterio de Corominas, los prejuicios intelectualistas y los reduccionismos naturalistas, pero también los antropologismos de la praxis en que cae Gramsci y todas las filosofías del sujeto. Desde el acto puro, como punto de partida radical para la filosofía, Corominas pide eliminar la carga metafísica de la noción de praxis, para no adscribirla a una teoría metafísica o a una teoría del sujeto en particular"2. Con ello pasa direclamente a fundamentar el carácler material de los actos, anterior a toda tesis melafísica o epistemológica: "Estamos seguros de la materialidad de los actos, pero no estamos igualmente seguros de una realidad material o de una realidad espiritual exterior a los mismos. Aquí equidistamos tanto de un realismo metafísico como del idealismo moderno"'s? Esta afirmación nos ubica en un nuevo horizonte, por lo menos de análisis filosófico. Ello le lleva a pasar de la filosofía primera a la metafísica, una teoría sobre la realidad en tanto que realidad"4, que en el tema que se expone, es una teoría racional de la materia allende. Esto en Zubiri es materismo en contra de materialismo. Materismo porque efectivamente todo parte de la materia, pero no todo se reduce a la materia (como enseña el materialismo). Esta teoría, a su vez., corrige las desviaciones filosóficas de recurrir a 'sustancias' entificando la realidad, cuando Zubiri sugiere que sólo la unidad cósmica es sustancial, mientras que 
todo lo demás es 'sustantividad' y 'respeclividad'.

Una valoración al respecto podemos decir que si bien es cuestionable el punto de partida radical de la filosofía como metafísica, ello no nicga el carácter racional de las tesis metafísicas, sean cuales sean. En este caso, la 'filosofía de la realidad histórica' de Ellacuría es pretendidamente una melafísica puesto que Ellacuría entendía la filosofía como metafísica".". Simplemente se trata de niveles diferentes de aproximación filosófica: uno primero, la inmediatez de todo acto, y otro segundo, en cuanto que es construcción racional de una realidad aprehendida en aquella inmediatez de los actos. En el caso de Ellacuria, aunque exprese que la realidad histórica es un materialismo abierto, hay que considerar su apropiación de la teoría materista de Zubiri y dejar claro que efectivamente entendió que si bien todo parte de la materia, no todo se reduce a la materia, y la historia vendría a ser la imbricación entre lo material y lo no material. Pero esta defensa es motivo de su debida investigación, fuera de los límites hasta aquí propuestos.

-IIéctor Samour, Una filosofía para la vida, (ECA 625-626, Noviembre-Diciembre 20(0), pp. $1129-1164)$.

El autor presenta en este artículo el capítulo segundo de su tesis doctoral"w, en el que trata la filosofía juvenil de Ellacuría hasta que conoce a Xavier Zubiri. Su relevancia consiste en poner a disposición del público en general su investigación acerea de la filosofía del joven Iillacuría. A diferencia de las tesis que presentó Roberto Valdés" , el autor nos relata las inquieludes del joven filósofo guardando eoherencia entre hipótesis y fundamentos. (ahe resaltar que los intereses intelectuales de Ellacuría en esta época responden en huena parte a las exigencias académicas de su proceso de formación, por un lado, y los nuevos vientos que empezaba a vislumbrarse en la Iglesia y en la misma companía de Jesús, por otro.

Se trala del periodo que va desde 1950) hasta 1962, donde Ellacuría realiza sus estudios de humanidades y lilosolía en Ouilo, enseña lilosolía en el seminario San José de la Monlaña, en San Salvador, y esludia teología en Innsbruck" ${ }^{\text {"N. }}$. El alán del joven Ellacuría consiste en realizar una filosolía a la altura de los liempos, que sintelizara lo anliguo con lo moderno, y que diera respuesta a los problemas vilales y existenciales del ser humano en las sociedades capilalistas modernas ${ }^{(k)}$. El esquema va así: Primero, reconoce la lormación inicial de Eallacuría en la neocscolástica, sobre todo como intento de sintetizar a santo Tomás con Kant, Bondel, Bergson, Ilusserl o lleidegger. Aquí entran las influencias intelectuales de Aurelio Espinosa Polit y Ángel Martínez. De ellos recibe la preocupación por lo humano, por los efectos de la sociedad capilalista, y el rigor por lo científico y filosólico acompañado de lo vital y concreto de la existencia ${ }^{1 n}$. Segundo, de lo anterior se resaltan las dos preocupaciones de Cellacuria: la filosofía como lorma de vida y la larea humanizadora de la lilosolia"in. Tercero, las exigencias de Ellacuría para la lilosolía hace que concuerde con mucho de los

Ellocuría después de Ellocurio El diálogo filosófico posterior a Ellocurio 
puntos del tomismo y la necesidad de sintetizarlo con el existencialismo contemporáneo, más en concreto, con el raciovitalismo de (Ortega y Gasset. Del tomismo reconoce su afán de fundamento hacia un auténtico humanismo, pero critica su rigidez dogmática, escolástica e idealista. De Ortega valora su afán de ser 'intelectual de la vida', pero critica su superficialidad. Se decide entonces por una reconciliación como complementación jerárquica entre ambas posturas. Para ello, somete la antropología de Ortega a los fundamentos tomistas. Trata temas como: la fundamentación de la apertura del ser humano; la vida humana como naturaleza e historia (y aquí: la vida humana como proyecto; la vida humana como choque dialéclico entre hombre y mundo; la vida humana como problema; la vida humana como realidad radical) ${ }^{11 ! 2}$. ('uarlo, por último constata la inviabilidad de su proyecto de síntesis, al intentar definir una realidad histórica-existencial de Ortega desde las categorías naturalista-esencial de la Escolílical"1.? Quinto, por fin, conoce a Zubiri y lo entiende como "trans-escoláslico y trans-filosofía actual", cuya filosofía era capaz de explicar al hombre como naturaleza e historia ${ }^{114}$. Y sexto, el autor concluye señalando los aspectos principales de la filosofía juvenil de Ellacuría en cinco puntos: la filosolía como forma de vida; el problema existencial del hombre contemporáneo como punto de parlida; la filosofía como metafísica; su búsqueda de una visión unilaria, dinámica y abierta de la realidad que integre los momentos de naturaleza e historia; y la orientación hacia la consideración de la historia como lugar pleno de realidad"'s.

\section{El diálogo posterior a Ellacuría. Conclusiones}

Hemos hecho hasta ahora un esfuerzo de invesligación, análisis y recensión de los 16 artículos publicados en la revista ECA que tocan de una u otra forma el pensamiento filosófico de Ellacuría. A continuación sistematizaremos este esfuerzo en tres bloques: los que exponen la teoría de Ellacuría; los que utilizan a Ellacuría como referencia para reflexionar una problemática en especifico; y los que hacen debate frontal a las tesis del mismo Ellacuría. Veamos entonces hasta dónde ha dado de sí la reflexión en torno al pensamiento ellacuriano:

\subsection{Los artículos que exponen la teoría ellacuriana}

En este apartado encontramos ocho artículos que se preocupan en exponer las características fundamentales del pensamiento de Ellacuría. Los arlículos son: Aproximación a la obra filosífica de Ignacio Ellacuria, de Antonio (ionzílez; Ignacio Ellacuria, filósofo de la realidad latinoamericana, de Manuel Domínguez; El legado filosófico-político de Ignacio Ellacuría, de Carlos Acevedo; IIistoria, Praxis y Liheración, de Héctor Samour; Ignacio Ellacuria: de la liberación de la filosofía a la filosofia de la liberación, de Rolando Alvarado; El método de historización de los conceptos de Ignacio Ellacuria, de Omar Serrano; Los es- 
critos estéticos de Ignacio Ellacuría, de Ricardo Roque Baldovinos; y Una filosofía para la vida, nucvamente de IJéctor Samour.

Las temáticas más tratadas han sido las siguientes: (1) La relación ZubiriEllacuría; (2) La preocupación de Ellacuría por una filosofía para $\wedge$ mérica lalina; (3) La historia como objeto de la filosofía; (4) La idea de filosofía política en Ellacuría y los rasgos de la filosofía de la liberación; y (5) La filosofía como modo de vida en Ellacuría.

Las temáticas menos tratadas son variadas: la formación inicial de Ellacuria, la historia como nuevo horizonte para la filosofía, el método de historización de los conceptos, la metafísica y la epistemología de Ellacuría, su idea de la civilización del capital y de la civilización de la pobreza, su idea de filosofía cristiana y sus escritos estéticos.

\subsection{Los artículos que hacen referencia a Ellacuría para reflexionar una problemática en específico}

En este apartado tenemos cinco artículos: la crítica cristiana a la civilización del capital, de Rafacl Díaz-Salazar; Orden Mundial y liberación, de Antonio González; Marco téórico-práctico para la construcción de un orden democrático en El Salvador, de Héctor Samour; Crítica radical al neoliheralismo, también de Héctor Samour; y El aporte de la filosofía latinoamericana a los derechos humanos, de Sajid Herrera.

El planteamiento más utilizado de Ellacuría como referencia ha sido su valoración ética de inviabilidad universal del capialismo y la necesidad de plantear una 'civilización de la pobreza' como horizonte utópico y critcrio de valoración ética, que expresa en Utopia y Profetismo desde América Latina.

Además los escritores han utilizado los conceptos de historia y libertad de Ellacuría contrastándolos con los de Fukuyama y del liberalismo. También han retomado la valoración que hace de la democracia como fachada en la época de la guerra y de las masas populares en El Salvador. Por último, señalan su aporte a la teorización de los derechos humanos, especialmente desde su método de historización de los conceptos.

\subsection{Los artículos que han generado debate en torno a Ellacuría}

Por último, nos encontramos con Ires artículos: La c'volución del pensamicento filosófico de Ignacio Ellacuría, de Roberto Valdés; Fundaménıos filosóficos de la civilización de la pohreza, de Antonio González; y Materia y praxis, de Jordi Corominas.

Del primero sólo queremos señalar que el artículo de Roberto Valdés contrasta con las conclusiones a las que llega Héctor Samour en su tesis doctoral,

Ellocurio después de Ellocurio El diálogo filosófico posterior a Ellocurio 
sobre la filosofía juvenil de Eallacuría. Las lesis de Valdés no están de lodo claras según Samour, debido a que no es apropiado combinar distintos saberes (filosolía con teología) para describir una evolución. Nosotros pensamos, además, que Valdés llega a conclusiones cilando unos texlos, de los que no se puede inferir realmente lo que se concluye.

Del segundo, nosotros lo valoramos como una prolongación del pensamiento de Zubiri. Antonio (ionzález. señala que para ser fiel a Ellacuría lo que se necesita no es asumir sus tesis así por así, sino su filosofar como modo de vida. Y a partir de tal convicción recupera la idea ellacuriana de la 'civilización de la pobreza' como horizonte utópico, pero sobre todo como 'modo alternalivo de sociedad', e intenta fundamentarlo desde su praxeología. El ser humano tiene unas estructuras éticas que le permiten, desde la razón, trazar líneas hacia un auténtica universalidad y eshozar una 'civilización de la pobreza' posible y justa para todos y todas.

Del tereero ya nos hemos referido en su recensión. Su referencia explícila a E:lacuría llama la atención. En el fondo hay tres pugnas que le hace a Ellacuria: la tensión entre compromiso ético con las víctimas de todo poder y el quehacer más propio y técnico de la filosolía sin pretensión de electividad inmediata; la idea de una filosofía primera que sea praxeología y de muchas filosolías segundas, una de ellas que sea melalísica; y la posible discusión si Ellacuría queda como un 'materialista, aunque séa abierto' o si asumió completamente la 'malcridad' que Zubiri habla para corregir la desviación melalísica de que lodo es materia. La primera es una invilación de parle de Ellacuría de mantener lal tensión. La segundo puede quedar resuclta de manera analíticamente jerárquica, es decir, como dos niveles de análisis distintos, uno de ellos desde la aprehensión primera de los actos y el otro desde la facultad de la razón de construir teorías acerca de lo allende a los actos. De la tercera creemos que Ellacuría no queda alrapado en la materialidad sino que efectivamente entendió la teoría 'materista' de Zubiri. 


\section{Anexo}

\section{Proyecto de investigación: \\ Ellacuría después de Ellacuría \\ El diálogo filosófico posterior a Ellacuría}

\section{Ohjetivo general:}

Sistematizar los estudios publicados que hacen diálogo acerca de la filosofía de Ellacuría en los distintos medios - libros y revistas- de nuestra universidad.

Ohjetivos específicos:

-Enumerar y elaborar recensiones sobre las diversas tesis filosóficas sobre la inspiración de la filosofía ellacuriana.

-Enumerar y elaborar recensiones los diversos arlículos filosóficos publicados en la UCA alrededor de la filosofía ellacuriana.

-Enumerar y elaborar recensiones los distintos prólogos de las obras publicadas de Ellacuría.

- Extraer conclusiones sobre la base del trabajo realizado con miras a fomentar el deseo de la investigación y aclualización de Ellacuría.

Posihles lecturas sujetas a sistematizacion:

- Lo publicado en ECA, por año:

1990

1992

1993

1994

1997
A. González

M. Domínguez

R. Díaz-Salazar

C. Acevedo

R. Alvarado

H. Samour
A. González

H. Samour

II. Samour

O. Serrano

R. Valdés

R. Roque B.

J. Corominas
Aproximación a la obra filosófica de I.L:

I.E., filósofo de la realidad latinoamericana

La critica cristiana a la civilización del capital El legrado filosófico-politico de l.E.

I.E.: de la liberación de la filosonfia a la filosonfía de la liberación

Ilistoria, praxis y liberación e'n el pensamiento de l.I:

Orden mundial y liberación (?") ${ }^{114,}$

Marco teórico-práctico para la construcción de un... (?)

Critica radical al neoliberalismo (?)

El método de historización de los conceptos de I.E.

La cvolución del pensamicento filosófico de l.E.

Los cescritos estéticos de l.l. ("?)

La universalidad de la reflexion ética mesoamericana (?)

Ellocurio después de Ellocuría El diálogo filosófico posterior a Ellacurio 
A. González

S. Herrera

$1998 \quad J$. Corominas

J. Corominas

J. Corominas

1999) J. Corominas

J. Corominas

$2000 \quad J$. Corominas

H. Samour
Fundamentos filosóficos de la civilización de la pohreza

El aporte de la filosofía latinoamericana a los DH (?)

Hacia la construcción de un proyecto de sociedad alternativo. (?)

¿Social democracia o socialismo de mercado? (?)

La marcha de los Nibelungos y la élica de la responsabilidad (?)

Diversidad de culturas, igualdad de derechos (?)

Materia y Praxis

Sociedad mundial y democracia (?)

Una filosofía para la vida

- Arlículos filosóficos en página WEB de la UCA y no publicados c'n ECA:

- Sócrates, Gramsci y Ellacuria

- Ellacuría y X. Zubiri: La pasión por la verdad. (Jordi Corominas)

- Ignacio Ellacuría: Filosofía y liberación e'n América Latina. (Carlos Molina)

- Sobre los modos de filosofar. (Sajid Herrera)

- I. a filosofía temprana de Ignacio E:llacuría. (Héctor Samour)

- Civilización de la Pobreza: I a radicalidad del último E:llacuría. (Ricardo Ribera)

- Incidencia de la teología de la liberación en la filosofía latinoamericana (R. Fornet-Betancourt)

Tesis de licenciatura sohre la inspiración de la filosonfia de l.L.:

- Ilacia una conceptualización salvadoreña de los derechos humanos según Ignacio Ellacuría

Wilmer Ramón Percira Castro (T-2816* P4.36 - 1991)

- La idea de liheración e'n Ignacio Ellacuria

Francisco Morales, Allen Palacio ('l-2879* M828 - 1992)

- El ideal de sociedad democritica, según la filosofia politica de Ignacio Ellacuría

Teófilo Argucta Ramírez. ('T-3()2.3 - 199.3) 
- El carácter político de la filosofía en Ignacio Ellacuría

Francisco José Domínguez Moreno (T-3070) - 1994)

- Reforma hancaria salvadoreña en el periodo de 1979-1992 a la luz de la filosofia de la liberación de I.E.

Carlos Eduardo Dimas Hernández ... [et al.] (T-3069) - 1994)

- La politicidad de la universidad y su fundamentación filosófica desde cl pensamiento de Ignacio Ellacuría.

Erasmo Oswaldo Ayala Perdomo, Oscar Antonio Navas Landaverde, Juan Francisco Quintanilla (T-3306 - 1995)

- Introducción al pensamiento ético de Ignacio Ellacuría

Carlos Luis Nuñez Madrigal (1'-3.359 - 1996)

- Siete tesis en Iorno al mélodo filosófico de Ignacio Ellacuría: La historización de los conceptos

Ernesto René Wauthion Delgado (T-3.367 - 1996)

- Propuesta pedagógico-metodológica para una mejor conseñanza-aprendizaje de la filosofía a partir de la práctica docente de Ignacio tillacuría y de algunos de sus escritos filosóficoss

César Giovani Moreno Coto ('T-3561 - 1997)

- Sistematización del concepto de ideología en la filosofía de Ignacio Ellacuria

Jefrin Omar Rodríguez Escalón (T-3619 - 1997)

- Aproximación a la critica de Ignacio Ellacuria a la civilización del capital Ronic Zamor ('T-36.3.3 - 1997)

- Aproximación al concepto de historia cen filosofía de la realidad histórica de Ignacio Ellacuria

- Guillermo Francisco Mata Bennett (T-36.37 - 1997)

- El problema del sujeto de la historia en Ignacio Ellacuria

Mario Edgardo Rivas Polanco (T-385.5) - 1998)

- Historia de la salvación de la historia en Ignacio Ellacuria

Ilugo C. Gudiel (T-3857 - 1998)

- Filosofía social en Habermas y Ellacuria

Anneo Rodríguez (T-4226 - 20)(0)

Ellocurio después de Ellocurio El diálogo filosófico posterior a Ellocurio 
Tesis doctoral:

- Voluntad de liberación: Génesis y constitución del proyecto de filosonfía de la libęración de I.E.

Héctor Samour, 200()

Prólogos a sus obras:

- Filosofía de la Realidad Histórica: Antonio González.

- Escritos Filosóficos: Tomo I: Departamento de Filosofía de la UC.A. Tomo II: Carlos Molina Velásquez.

- Escrisos Políticos: Rodollo Cardenal

Otros libros:

- Ellacuría y los derechos humanos

Juan Antonio Senent de Frutos; prol. de Antonio González. Ferniínclez. (B1026.A6* S475 Bilbao, Esp. :1998).

- Ignacio Ellacuria, 'Aquella liberiad esclarecida'

Jon Sobrino/Rolando Alvarado (eds.)

(Sal Terrae, Santander, 1999).

\section{Notas}

I. Ver Ancxo.

2. Antonio Gonzálcz, Aproximación a la obra fillosoifica de Ignacio lillacuria. F('A 505-506, Novicmbre-Dicicmbre 19()), p. 980).

3. Id. p. 982

4. (T. Id. p. 983

5. Id. p. 984

6. II. p. 98.5

7. II. p. 984

8. II. p. 987

9. Manucl Dominguez. Miranda, Ignacion l: llacuria, filósofo de la realidad latimenamericama. F.(A 529-530, Novicmbre-I)iciembre 1992, p. 98.5.

10. Id. p. 986

II. II. p. 987

12. Id. p. 988

13. Id. p. 989. (F.1 autor cital a Fllacuria: Ilacia una fundamentacion del método teológicolarimoamericano. F('A 1975, p. 418).

14. Raliacl Díaz-Salazar, La critica cristicuma a la civilizacion del capital. Aportación de

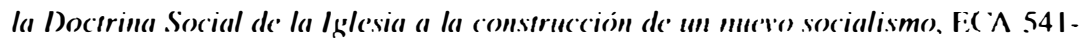
542. Novicmbre-I)icicmbre, p. 100)( 
15. Cr. Carlos Acevedo, El legado filosófico-politico de Ignacio t:llacuria, LC $\triangle 541$ 542, Noviembre-Diciembre 1993, p. 1091. (Acevedo también cila a Lilacuría. 197.5)

16. Id. p. 1091

17. Id. p. 1092

18. Id. p. 1092 (Cita a Ellacuria, Zubiri en El Salvador, p. 950)

19. Id. p. 1093 (Cila a Rodolfo ('ardenal, Ser.Jesuita hoy en El Salicador, E( A 1984), p. 1015)

20. Id. p. 1093

21. Más adelante Antonio González, en la mayoría de sus obras parte siempre de un análisis fáctico original.

22. Cf. Id. p. 1097 (Cita a Ellacuría, Introducción crítica a la antropologia de Xenier Zuhiri, p. 95).

23. Id. p. $11(0) 1$

24. Id. p. $11(02$

25. Héctor Samour, Filosofía y Libertad, In: Jon Sobrino/Rolando Alvarado (eds.), Ignacio Ellacuría, 'Aquella libertad e'sclarecida', Sal Terrae, Santander 1999, pp. 89-121.

26. Cf. Héctor Samour, Historia, praxis y liberación en el pensamiento de Ignacio Ellacuría, LCA 54 1-542, Noviembre-Diciembre 1993, p. $11(09$.

27. Id. p. 1109

28. Id. p. 1113

29. Id. p. 1113. (Cita a Ellacuria, Función liheradora de la filosofia, 1985, p. 110)

30. Cf. Id. p. $1115-117$

31. Id. p. 1120

32. Cr. Id. pp. 1120)-1124

33. Rolando Alvarado, Ignacio Ellacuria: de la liberación de la filosofia a la filosofía de la liheración, LCA 541-542, Noviembre-Diciembre 1993, pp. 1129.

34. Id. p. 1130. (Cita a Ellacuría, Ia superación del reduccionismo idealista en Zuhiri, E(^ 447, I)88, pp. 6.3.3-6.5()).

35. Id. p. 1132

36. Id. p. 1130 (Alvarado hace su investigación desde tres fuentes de Lllacuria: IFilosofía $y$ política; los esquemas inéditos para escribir un artículo llamado la filosofia como sintesis de la vida intelectual y la vida politica; y los esquemas también inéditos sobre un curso que impartici en la UC $\Lambda$ antes de 1987 Ilamado Antropologia politica).

37. Cf. Id. p. 1132

38. Id. p. 1135

39. Cf. Id. p. 1136-11.37

40. Id. 1138

41. Id. p. 1140

42. Antonio González, Orden mundial y liberación, ECA 549, Julio 1994, pp. 6.30 y 6.34.

43. Id. p. 630

44. I. Ellacuría, Utopía y Profetismo desde América Latina, Revista Latinoamericana de Teologia, 17, 1989, p. 1.52-15.3.

Ellocurio después de Ellocuría El diólogo filosófico posterior a Ellocurio 
4.5. A. González, Orde’n mundial y liheración, Op. cit., p. 6.34.

46. Héctor Samour, Marco teririco-práctico para la construccioin de un orden democrático e'n El Salvador, LC( $\wedge$ 54.3-544. I:nero-Febrero 1994. p. 38. (Cilia a Ellacuría, I.a fachada democrática, L( $\wedge$ I)88).

47. Id. p. 51-5.3. (Cita a Lillacuria, La cuestion de las masas, Le( A 1987).

48. Iléctor Samour, Critica radical al meoliberalismo, E(A 5.52, Octubre 1994. p. 1088

49. Id. p. 109$)$

50. Omar Serrano, El método de historizacion de los conceptos de lgnacio l:llacuria, H(A 55.3-5.54, Novicmbre-Diciembre 1994, p. 124.5.

51. Id. p. 1245. (Los artículos Lllacuría investigados son: La historización del concepto) de propiedad como principio de desideologizacion, ECA 33.5-336, 1976. pp. 42.5450); La historización del hic'n común y de los derechos humanos c'n una sociedad dividida, In: Lisa Torres y Saúl Trinidad, Capitalismo: violencia y anti-ivida. Costa Rica 1978. pp. 81-94: La historizacion de los derechos humanos desde los puchlos oprimidos y las mayorías populare's, ECA 5(22, 199(), pp. 589-59(2).

52. ('T. Id. p. 1247

5.3. Id. p. 1248. (Cita a Zubiri, Sobre la escencia, Madrid 1962, p. 14.3).

54. Id. p. 1249

55. Hay que señalar además que este arlículo hal aparecido, con ligeras modilicaciones, en la recopilación de Jon Sobrino y Rolando Alvarado. Ver: Roberto Valdés. I.a húsqueda filosófica inicial, In: Jon Sobrino/Rolando Alvarado (eds.). Ignacio Ellacuria, 'Aquella liberiad esclarecida', Sal Terrae, Santander (9)99, pp. 5.3-78.

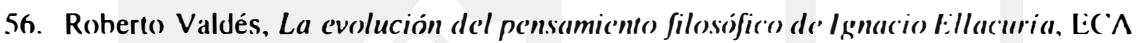
577-578, Noviembre-Diciembre 1996, pp. 1(1).30.

57. Id. p. 1031

58. Id. p. 10.34

59. Id. p. 1036

6(). Id. p. 1(0.39

61. Id. p. 1040

62. (T. Héctor Samour, Voluntad de liberacionn. Génesis y constitución del proyecto de filosofía de liberación de Ignacio Lillacuria. Tesis doctoral, UC`A 200(), p. 21.

6.3. Ricardo Baldovinos, los escritos estéticos de lgnacio Ellacuría, EC^ $577-578$, Novicmbre-Diciembre 1996, p. 1055. ("Pocsia de aqui y ahora" es el prólogo que Ignacio Ellacuría escribe para el poemario (Oriculos para mi raza de Rafacl Rodriguez Diaz, UC.A editores, 1985).

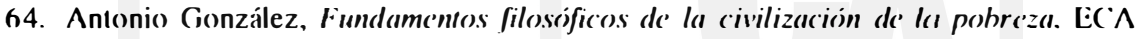
58., Mayo 1997, p. $41 \%$.

6.5. Id. p. 420

66. Id. pp. 420-421. (( 'ila a Ellacuría. Utopía y Profertismo desde América L.atina, pp. $41(1)-42())$

67. Id. p. 421

68. Id. p. 422

69. Id. p. 423 
70. Id. p. 423

7l. Id. p. 42.3

72. Id. p. 424

7.3. Id. p. 425

74. Id. p. 426

75. Id. p. 426

76. Sajid Herrera, lil aporte de la filosoffá latinoamericana a los derechos lummanos, L(A 589-590, Noviembre-1)iciembre 1997, p. 1157.

77. Id. p. 1158

78. Id. p. 1166

79. ( 1 . Id. p. 1166

80. Id. p. 1166

81. ('T. Jordi Corominas, Materia y Praxis, $\mathrm{EC} \wedge$ 61.3-6/4, Noviembre-Diciembre 1999, p. 1010

82. ( T. Id. p. I0)I

8.3. (i. Id. p. I0II

84. Id. p. 1012

85. (T. Id. p. 10)13-10)14. (Ísio lo Iralal extensamente en Iesis doctoral Ética primera:

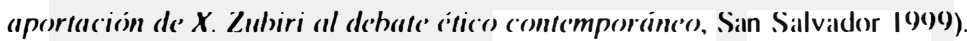

86. Id. p. 1015

87. Id. p. 1016

88. ('. p. $1011-1012$

89. Id. p. 1016

90. (ใ. Id. p. 1018

91. (i. Id. p. I019)

92. (f. Id. p. 1020

9.3. Id. p. 1024

94. Id. p. 1027

95. Ver la lesis doctoral de Héctor Samour.

96. Héclor Samour, Volunlad de liheracion. (iénesis y constilución del proyecto de filosolïa de liheración de Ignacio Lillacuria. Tesis doctoral, San Salvador 2000). pp. 37-116.

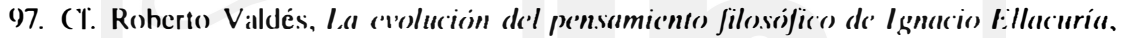
F.(A 577-578, Novicmbre-I)iciemhre 1906, pp. 1(1)30-1047.

98. Héctor Samour, Una filosofía para la vida, Lic 1 625-626. Noviembre-1)iciembre 2000, pp. 1129 .

99. (i. Id. p. 1129

100. ( $\%$. Id. pp. 11.30-11.34

IOI. ( $\%$ Id. pp. II.34-1 I.39)

IO2. (C. Id. pp. II.39-11.56

10.3. (f. Id. pp. $1156-1157$

104. (f. Id. pp. I157-II6.3

I0.5. ('T. Id. pp. I I6,3-1 I64

106. FI signo de interrogación signilica (jue está sujeto a investigación.

Ellocurio después de Ellocurio El diálogo filosófico posterior a Ellocurio 